\title{
Malignant melanoma of the nasal septum, a rare tumor, occurring in a 54-year-old patient after hereditary retinoblastoma treatment
}

This article was published in the following Dove Press journal:

International Medical Case Reports Journal

9 February 2016

Number of times this article has been viewed

\author{
Windinmanégdé Pierre \\ Djiguimdél \\ Ibrahim Abib Diomandé ${ }^{2}$ \\ Nicolas Bonnin ${ }^{3}$ \\ Nicolas Saroul ${ }^{4}$ \\ Abdoulaye Touré ${ }^{5}$ \\ Jérôme Sanou' \\ Paté Sankara' \\ Marc Russier ${ }^{4}$ \\ Laurent Gilain ${ }^{4}$
}

Ahgbatouhabéba Ahnoux-

Zabsonré

Nonfounikoun Meda'

Franck Bacin ${ }^{3}$

'Ophthalmology Department, University Hospital Yalgado

Ouédraogo, Ouagadougou, Burkina

Faso, ${ }^{2}$ Ophthalmology Department, University Hospital of Bouaké,

University Alassane Ouattara, Bouaké,

Cote d'Ivoire, ${ }^{3}$ Ophthalmology

Department, ${ }^{4}$ Otorhinolaryngology

Department, University Hospital

Clermont-Ferrand, Clermont-Ferrand,

France; ${ }^{5}$ Radiology Department,

University Hospital of Yopougon,

University Félix Houphouët Boigny,

Abidjan, Côte d'Ivoire

Correspondence: W Pierre Djiguimdé Ophthalmology Department, University Hospital Yalgado Ouédraogo, 03 Bp 7022, Ouagadougou 03, Burkina Faso Email pierredjiguimde@yahoo.fr

\begin{abstract}
The authors report a case of a malignant melanoma of the nasal cavity that is a rare tumor and very aggressive, constituting $1 \%$ of all melanomas. It appeared in a patient 54 years after he was treated for a hereditary retinoblastoma. Its symptoms are nonspecific, and often marked by epistaxis. Its diagnosis is histological, supported by immunohistochemistry. Its prognosis is often unfavorable, and characterized by the occurrence of metastases and recurrences. Because of the risk of secondary cancer that exists in any survivor of hereditary retinoblastoma, we must think of possible mucosal melanoma of the nasal sinus in these patients in cases of chronic epistaxis. The prognosis of this tumor depends on its early diagnosis and surgical treatment.
\end{abstract}

Keywords: retinoblastoma, epistaxis, immunohistochemistry, nasosinusal melanoma, hereditary cancer

\section{Introduction}

Malignant melanoma of the nasal cavity is a rare, aggressive tumor, representing 1\% of all melanomas and $4 \%$ of sinonasal malignancies. Its occurrence among hereditary retinoblastoma survivors may be more common than in the general population, due to their genetic predisposition to cancers related to $R B 1$ gene mutation. ${ }^{1}$ The clinical features are dominated by a nasal obstruction and often unilateral epistaxis. The prognosis of sinonasal melanoma is formidable, with a 5-year survival of less than $30 \%$. The diagnosis is histopathological and immunohistochemical. ${ }^{2}$ Surgical treatment should be radical.

\section{Observation}

In April 2012, the ENT (ear, nose, and throat) Department at the University Hospital of Clermont-Ferrand examined a 54-year-old patient suffering from a blood discharge of the right nostril progressing over a couple of months. In the patient's personal history, there was a retinoblastoma of the right eye at the age of 7 months, which received enucleating treatment followed by radiotherapy (two doses of $40 \mathrm{~Gy}$ in 18 fractions and 14 fractions, by small fields of $4-6 \mathrm{~cm}^{2}$ ), due to the radiation-induced sequelae of the right hemifacial requiring multiple reconstructive surgeries and a prosthetic device.

He is under levothyroxine treatment after a thyroidectomy for a benign tumor, carries a defibrillator, and is being treated for hypotension. The patient has also smoked since the age of 16 years (approximately 35 packs per year) and has presented three episodes of "angioneurotic" edema following an allergic reaction to penicillin. In the family history, his mother has breast cancer. A bilateral retinoblastoma detected in his 
daughter at the age of 3 months was treated by enucleation of the left-eye and right-eye radiotherapy (45 Gy in 24 sessions over 32 days) associated with chemotherapy, which led to a sarcoma pleomorphic undifferentiated in the irradiation zone, and was treated with surgery and chemotherapy.

The ENT examination revealed at the right nostril a blackish tumor on the anterior part of the nasal septum. The left nasal cavity was normal, the orbital floors were free, and the examination of the cervical area was normal. The computed tomography scan found thickening tissue of the right nasal cavity remaining confined without any suspicious abnormality (Figure 1). No magnetic resonance imaging
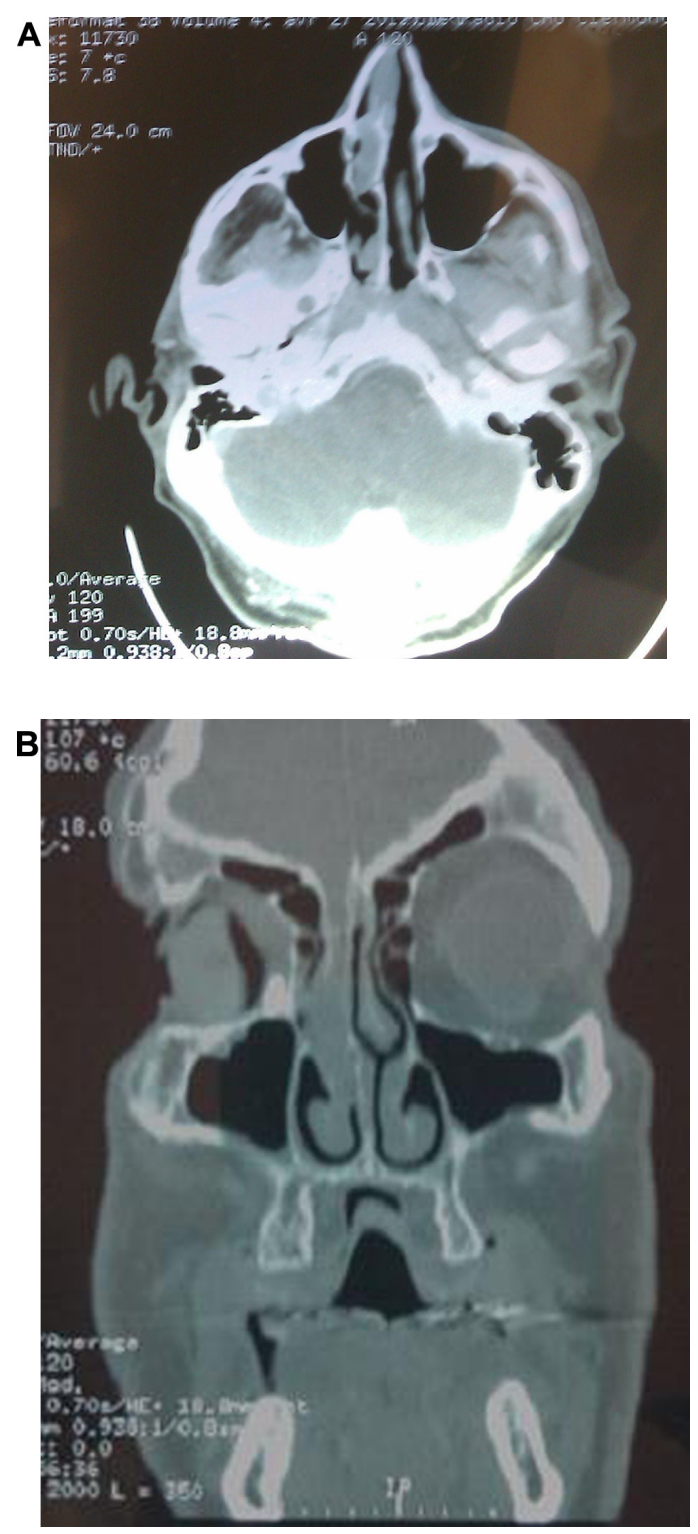

Figure I Preoperative CT scan showing the nasal tumor.

Notes: (A) Axial computed tomography scan of sinus with a parenchymal opening; (B) coronal bone with an opening showing a thickening tissue of the right nasal cavity. was done, because of the presence of the defibrillator. The biopsy performed under local anesthesia with a histopathological analysis of the sample reported a malignant melanoma globocellular type of nasal septum (Figure 2). An endonasal resection performed with immunohistochemical examination confirmed the diagnosis of malignant melanoma. The lesion was strongly expressing vimentin and human melanoma black 45 (HBM45) (Figure 3). It was an epithelial membrane antigen (EMA) and negative pankeratin. Surgery on the tumor was performed under general anesthesia by the endonasal route, with excision of the tumor in one piece and all the nasal septum. Extemporaneous examinations were performed on all incision samples, which yielded negative results. A consultation was performed in addictology in order to help the patient stop smoking. The anatomopathological analysis of surgical specimens confirmed the malignant melanoma $(1.5 \mathrm{~cm}$-long axis, infiltration and ulceration of the right nasal cavity, globular cells of an epitheloid appearance rich in cytonuclear irregularity, large nucleus with nucleolus strongly thickened with nuclear membrane and a coarse chromatin with mitosis), which came into contact with the overlap of the lower septum (Figure 4). Adjuvant radiotherapy of 54 Gy was delivered in 18 fractions of 3 Gy. Clinical (ENT, ophthalmology, medical) and radiological (computed tomography, chest X-ray, ultrasound) examinations performed every 3 months were unremarkable (Figure 5). This case report followed the tenets of the Declaration of Helsinki and was approved by the Center Hospital University of Clermont-Ferrand ethics committee. Written consent was obtained from the patient.

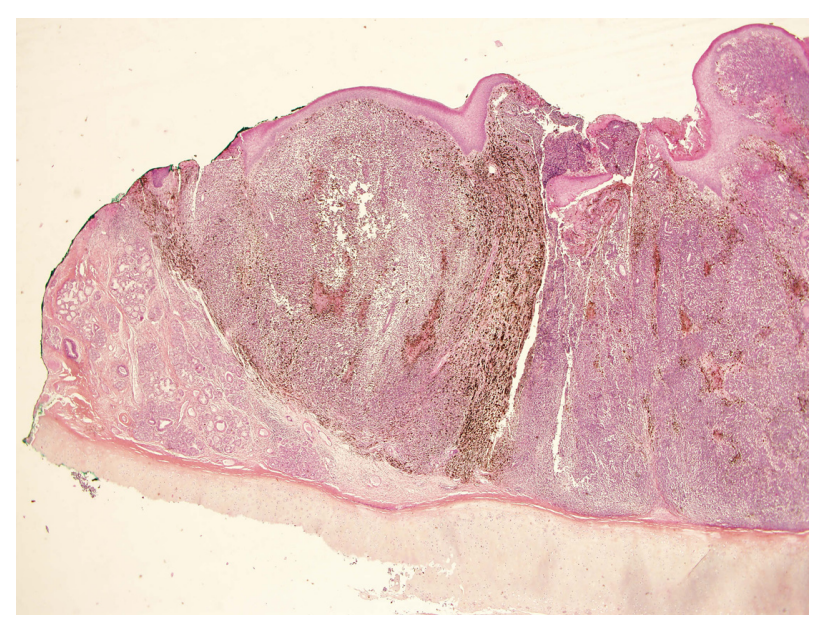

Figure $\mathbf{2}$ Infiltration of the right nasal cavity wall with a melanoma arriving in depth to the cartilage without invading it.

Notes: Hematoxylin-eosin-saffron staining (magnification $\times 2$ ). Image courtesy of JL Kemeny.

Abbreviation: hematoxylin-eosin-saffron. 


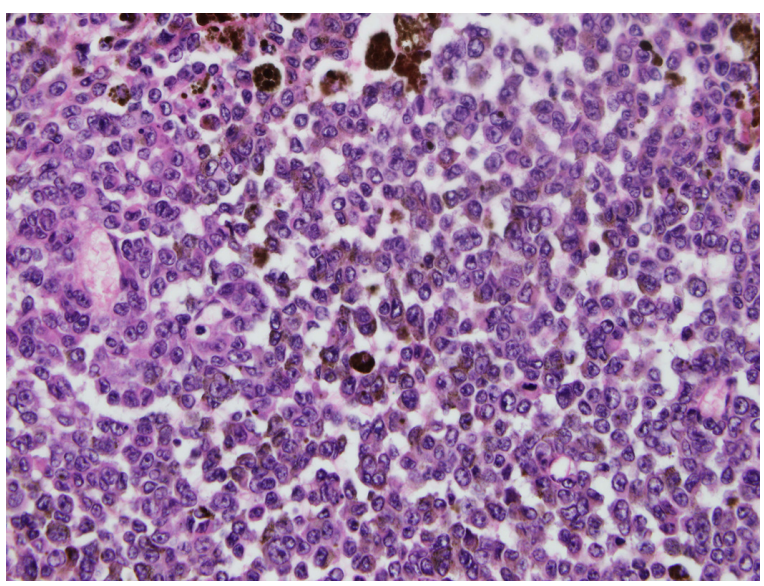

Figure 3 Detail of tumor melanoma cells that have an atypical nucleus. Note: Image courtesy of JL Kemeny.

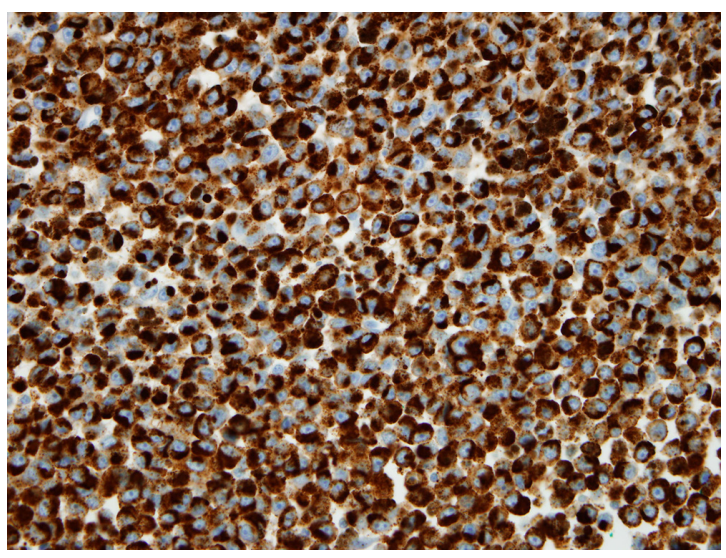

Figure 4 Brown marking of intracytoplasmic tumor cells with HMB45 and melan A in immunohistochemistry on paraffin section (magnification $\times 40$ ). Note: Image courtesy of JL Kemeny.

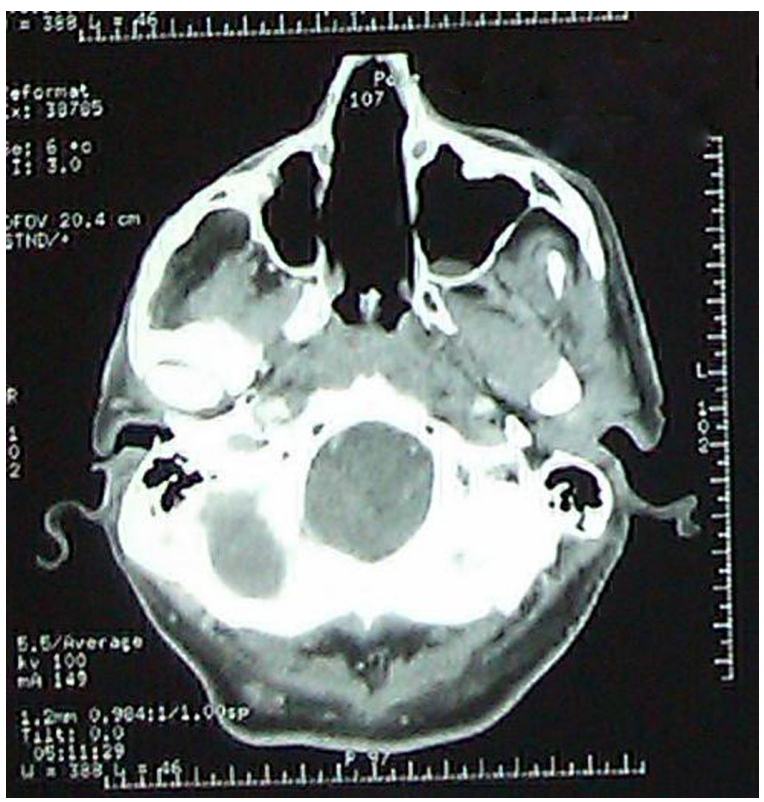

Figure 5 Postoperative computed tomography showing empty nasal cavities.

\section{Discussion}

Thanks to long-term survival rates observed more and more in patients treated for retinoblastoma; it is not rare to see the emergence of a second primary cancer after radiotherapy. ${ }^{3}$ The retinoblastoma prognosis is excellent these days, since more than $90 \%$ of children are cured in industrialized countries ${ }^{4}$ with possible preservation of visual function. The current problem is the risk of developing a second cancer, as observed in our patient. It has been shown that the probability of developing a second cancer was higher in subjects with a previous history of hereditary retinoblastoma, and that the risk would be even higher in cases of bilateral retinoblastoma. ${ }^{6}$ Patients presenting with retinoblastoma with a family history of retinoblastoma have an even higher risk, with a statistically significant difference. The retinoblastoma diagnostic age is also a factor that increases the risk of developing a second cancer. In fact, the risk is higher before the age of 12 months and becomes weak after 24 months. ${ }^{6}$ Our patient was therefore a potential candidate. Data from the Dutch retinoblastoma registry on the risk of a second cancer occurrence in 668 retinoblastoma survivors examined between 1945 and 2005 also reported a higher risk in hereditary retinoblastoma. ${ }^{7}$ Indeed, after an average follow-up of 21.9 years, the relative risk of second cancer occurrence among hereditary retinoblastoma survivors was 20.4 , while that risk was only 1.86 in sporadic retinoblastoma. It appears undeniable that mutation of the $R B 1$ gene is involved in the genesis of other cancers in addition to the retinoblastoma, regardless of treatments administered.

In a study of the specific causes of death among survivors of retinoblastoma in a series of 1,854 patients between 1914 and 1996, Yu et $\mathrm{al}^{8}$ found higher cancer mortality among hereditary retinoblastoma survivors, especially sarcoma, melanoma, and nervous system cancer. There was no evidence of excess nonneoplastic death among the survivors. Very few studies report follow-ups about retinoblastoma survivors aged above 40 years. ${ }^{6}$ Our patient developed a second cancer 54 years after diagnosis and treatment of the retinoblastoma. He had no family history of retinoblastoma when examined, and tumor cytogenetic study was not performed at that time. It is the appearance of a bilateral retinoblastoma in his daughter that has facilitated the diagnosis of a hereditary retinoblastoma retrospectively in this patient. Cancers of the nasal cavities are reported in retinoblastoma survivors, but we have not noted in the literature a case of malignant melanoma of the nasal cavity. Cases of melanoma reported in different series are cutaneous melanomas that occur most often after the age of 20 years and often involve the 
role of solar ultraviolet rays. ${ }^{6}$ Primitive mucosal melanoma of the nasal cavity is a highly aggressive and rare malignancy constituting $1 \%$ of all melanomas. ${ }^{9-11}$ Its symptoms are nonspecific and its diagnosis is anatomopathological, supported by immunohistochemistry. ${ }^{10,12}$ This is a tumor that usually appears after the age of 60 years, regardless of sex predominance. The symptoms are often mild and nonspecific. The most common symptom is epistaxis, which should be of particular note if it is unilateral and persists over time. Its treatment is essentially surgical, based on a wide resection of the tumor. The prognosis is often unfavorable, characterized by frequent recurrence and metastasis and a survival rate at 5 years inferior to $30 \%$.

The pathogenesis is poorly understood, but some factors have been implicated, such as tobacco and formaldehyde (formalin). Sun exposure would play no role in the occurrence of these mucosal melanomas. ${ }^{9}$ The combination of several antecedents in our patient may have played a role in the occurrence of the nasal mucosal melanoma. The patient was a heavy smoker (35 packs per year) with an early age of onset at 16 years. Smoking has sometimes been implicated in the etiopathogenesis of sinonasal cancers. ${ }^{9}$ The involvement of X-rays in the occurrence of cancer is well established, and that is what currently limits its use for specific indications. It is possible that in 1958 the protection of neighboring organs was not optimal and that the nose of our patient received a certain dose of irradiation. According to Abramson, the cumulative incidence of a second cancer calculated over 50 years is approximately $1 \%$ per year. ${ }^{13}$

Our patient, having received an irradiation at 7 months, therefore has a high risk of a second cancer, especially after 54 years; however, it is difficult to say whether the nose was in the irradiation area or not.

\section{Conclusion}

Due to the high and cumulative risk of developing a second cancer in bilateral retinoblastoma survivors, any epistaxis in these patients must be examined carefully for early detection of a possible melanoma of the sinonasal cancer, because early diagnosis and surgical treatment will positively impact the prognosis of this condition.

\section{Disclosure}

The authors report no conflicts of interest in this work.

\section{References}

1. Desjardins L, Couturier J, Doz F, Gauthiers-Vilars M, Sastre X. Tumeurs de la rétine. 2003. [Retinoblastoma. 2003.] Encycl Med Chir Ophthalmologie. Paris: Elsevier SAS;2004:18-37. French.

2. Doz F. Rétinoblastome: aspects récents. [Retinoblatoma: a review]. Arch Pediatr. 2006;13:1329-1337. French.

3. Castéra L, Sabbagh A, Dehainault C, et al. MDM2 as a modifier gene in retinoblastoma. J Natl Cancer Inst. 2010;102:1805-1808.

4. Zografos L. Rétinoblastome [Retinoblastoma]. In: Tumeurs Intraoculaires. [Intraocular Tumors]. Paris: Editions Masson; 2002:463-619. French.

5. Desjardins L. Les tumeurs en ophtalmo-pédiatrie. Diagnostic et stratégie thérapeutique. [Ophthalmological tumors in children: diagnosis and therapeutic strategy]. J Fr Ophtalmol. 2000;23:926-939. French.

6. Kleinerman RA, Yu C, Little MP, et al. Variation of second cancer risk by family history of retinoblastoma among long-term survivors. J Clin Oncol. 2012;30:950-957.

7. Marees T, Moll AC, Imhof SM, de Boer MR, Ringens PJ, van Leeuwen FE. Risk of second malignancies in survivors of retinoblastoma: more than 40 years of follow-up. $J$ Natl Cancer Inst. 2008;100:1771-1779.

8. Yu C, Tucker MA, Abramson DH, Furukawa K, et al. Cause-specific mortality in long-term survivors of retinoblastoma. J Natl Cancer Inst. 2009;101:581-591.

9. Hariga I, Zribi S, M'barek CH, et al. Les mélanomes malins nasosinusiens. [Sinonasal melanoma]. J Tun ORL. 2006;16:50-52. French.

10. Lund VJ, Chisholm EJ, Howard DJ, Wei WI. Sinonasal malignant melanoma: an analysis of 115 cases assessing outcomes of surgery, postoperative radiotherapy and endoscopic resection. Rhinology. 2012;50:203-210.

11. Douglas CM, Malik T, Swindell R, Lorrigan P, Slevin NJ, Homer JJ. Mucosal melanoma of the head and neck: radiotherapy or surgery? J Otolaryngol Head Neck Surg. 2010;39:385-392.

12. El Mahfoudi A, Mharrech A, Elomrani A, Khouchani M, Tahri A, El Idrissi E. Mélanome malin des fosses nasales (à propos d'un cas). [Malignant melanoma of nasal mucosa (a case report)]. Rev Maroc Cancer. 2011;3:29-33. French.

13. Abramson DH. Second nonocular cancers in retinoblastoma: a unified hypothesis. The Franceschetti Lecture. Ophthalmic Genet. 1999;20: 193-204.
International Medical Case Reports Journal

\section{Publish your work in this journal}

The International Medical Case Reports Journal is an international, peer-reviewed open-access journal publishing original case reports from all medical specialties. Previously unpublished medical posters are also accepted relating to any area of clinical or preclinical science. Submissions should not normally exceed 2,000 words or

\section{Dovepress}

4 published pages including figures, diagrams and references. The manuscript management system is completely online and includes a very quick and fair peer-review system, which is all easy to use. Visit $\mathrm{http}: / /$ www.dovepress.com/testimonials.php to read real quotes from published authors. 